The aim of this case report is to depict a patient with locally advanced prostate cancer who was successfully switched from transdermal buprenorphine to oral, controlled-release oxycodone. A 79-year-old man was admitted to the palliative medicine out-patient clinic due to progression of prostate cancer after radical radiotherapy. His main complaint was pain in the perineum of severe intensity. The patient was treated with transdermal buprenorphine (TB) starting with the dose of $35 \mu \mathrm{g} / \mathrm{h}$, subsequently increased to $52.5 \mu \mathrm{g} / \mathrm{h}$ and finally to $70 \mu \mathrm{g} / \mathrm{h}$ but after 4 months analgesia was unsatisfactory. In addition, the patient experienced drowsiness. TB was stopped and oxycodone controlled-release $10 \mathrm{mg}$ twice daily was started, after 2 days increased to $20 \mathrm{mg}$ twice daily, achieving satisfactory analgesia and less drowsiness. No significant adverse effects were present apart from moderate constipation controlled with lactulose. The patient continues his regimen with success and improvement in his quality of life.

Key words: advanced cancer, adverse effects, cancer pain, opioid switch, oxycodone, prostate cancer, buprenorphine.

\section{Successful switch from transdermal buprenorphine to oral controlled- release oxycodone in a patient with locally advanced prostate cancer: a case report and review of the literature}

\author{
Wojciech Leppert
}

Chair and Department of Palliative Medicine, Poznan University of Medical Sciences, Poland

\section{Introduction - opioid switch}

The management of moderate to severe pain in cancer patients is based on opioid analgesics therapy combined with co-analgesics administration and application of non-pharmacological measures depending on the type of pain and tumour; the holistic approach also comprises treatment of other symptoms, and psychosocial and spiritual support [1, 2]. However, when a given opioid therapy fails opioid switch (OS) is one of the possible methods to achieve satisfactory analgesia without intense adverse effects [3]. The rationale of OS is associated with limited cross-tolerance between opioid analgesics and differences in pharmacodynamics and pharmacokinetics [4]. About $60-90 \%$ of patients benefit from changing opioids [5]. A similar result may also be achieved by changing the opioid route of administration, e.g. from oral or transdermal to subcutaneous, intravenous or intrathecal route [6]. OS is indicated when pain is not relieved in spite of escalating opioid doses. In most cases, however, severe adverse effects of opioids are an indication for OS [7]. There are no clear guidelines as to which opioids are best for OS [8]. In many studies methadone seems to be effective when morphine or other opioids fail [9]. However, methadone possesses complex pharmacokinetics and its dosing needs significant expertise in pain management [10]. There are concerns that QT prolongation may be present and in some patients may lead to increased risk of arrhythmia [11]. One of the commonly used opioids for moderate to severe pain is oxycodone. There is a lack of clinical data on switching from transdermal buprenorphine (TB) to oxycodone. A significant problem is dosing of a new opioid introduced. The aim of this case report is to depict a patient with locally advanced prostate cancer who was successfully switched from TB to oral, controlled-release (CR) oxycodone.

\section{Case report}

A 79-year-old man was admitted to the palliative medicine out-patient clinic due to progression of an inoperable prostate cancer. The patient underwent adenomectomy in 2003 due to prostate adenoma. In 2008 adenocarcinoma of the prostate was diagnosed and the patient was treated with radical radiotherapy. The patient has a history of hypertension and continues hormone therapy with goserelin acetate. In January 2011 the patient was referred to the Department of Palliative Medicine. The patient performance status was ECOG 2-3, Karnofsky 50-60. His main complaint was pain in the perineum of severe intensity. The pain was constant, located in the lower abdomen and perineum (8-9 on a numerical rating scale: 0 - no pain, 10 the most severe pain) that exacerbated during passing urine through the suprapubic cystostomy. His bone scintigraphy was normal. The patient also had normal results of renal and liver function tests, electrolytes and haemo- 
globin level. On admission despite treatment with non-opioid analgesics (paracetamol and ibuprofen prn) his pain was very severe. He started TB treatment with the dose of $35 \mu \mathrm{g} / \mathrm{h}$, subsequently increased to $52.5 \mathrm{\mu g} / \mathrm{h}$ and finally to $70 \mu \mathrm{g} / \mathrm{h}$; for breakthrough pain the patient was prescribed immediate-release (IR) morphine $10 \mathrm{mg}$. However, after 4 months of this treatment TB did not allow satisfactory analgesia (NRS 7) to be achieved although IR morphine (taken 3-4 times daily) provided some relief for 4-6 h. Other symptoms were weakness and loss of appetite. In addition, the patient experienced drowsiness. His regimen also comprised metoclopramide $10 \mathrm{mg}$ three times daily and valproate $500 \mathrm{mg}$ before sleep due to a history of a seizure episode.

At the beginning of May 2011 TB was stopped completely and the patient was switched to CR oxycodone at a dose of $10 \mathrm{mg}$ twice daily; IR morphine $10 \mathrm{mg}$ was maintained for breakthrough pain episodes. However, the pain decreased only to 5-6 according to NRS and after 2 days, the CR oxycodone dose was increased to $20 \mathrm{mg}$ twice daily. The pain relief was satisfactory this time (NRS 3-4) and in spite of the dose increase the patient was more alert than during TB therapy. The patient takes $10 \mathrm{mg}$ IR morphine once every three days on average for breakthrough pain episodes. No other significant adverse effects were present apart from moderate constipation that is controlled with lactulose $10 \mathrm{ml}$ twice daily. Appetite loss disappeared after dexamethasone administration $1 \mathrm{mg}$ in the morning. The patient has continued his regimen for 38 days with success until now with significant improvement of quality of life.

\section{Oxycodone}

Oxycodone is an opioid of step 3 of the analgesic ladder recommended by the EAPC (European Association for Palliative (are) as the first choice opioid for moderate to severe pain in cancer patients along with morphine and hydromorphone (Prof. Augusto Caraceni, personal communication). It displays a significant affinity to possibly $\kappa$ and $\mu$ opioid receptors. A combination of morphine and oxycodone produces antinociceptive synergy with less sedation in rats than equivalent doses of either opioid alone. Limited crosstolerance is observed between oxycodone and morphine in rats and in clinical studies. Oxycodone possesses similar lipid solubility to morphine but lower affinity to $\mu$ opioid receptors. Oxycodone permeates the blood-brain barrier very quickly [12]. It causes degranulation of mast cells and histamine release to less extent than morphine. Oxycodone does not display immunosuppressive effects in experimental studies [13].

Oxycodone displays high oral bioavailability (60-87\%). The volume of distribution of oxycodone $(2-3 \mathrm{l} / \mathrm{kg})$ is comparable to that of morphine. The $T_{1 / 2}$ is approximately 2-3 $\mathrm{h}$ after i.v. administration, $3 \mathrm{~h}$ after administration with IR oral solution and approximately $8 \mathrm{~h}$ after treatment with CR oxycodone tablets. The maximum plasma concentration $\left(c_{\max }\right)$ is reached within $25 \mathrm{~min}$ after i.v. injection, $1.3 \mathrm{~h}$ after IR administration and $2.6 \mathrm{~h}$ after administration of a CR formulation. The $C_{\max }$ after IR oxycodone administration is twice as high as an equivalent dose of CR oxycodone. The absorption of oxycodone is greater in women than in men.
The mean area under the curve (AUC) is $41 \%$ greater and the mean $C_{\max }$ is $35 \%$ higher in women compared with men. Women cleared oxycodone about $25 \%$ more slowly than men [13].

Oxycodone is metabolized in the liver primarily to noroxycodone through CYP3A4 and, to a much less extent, to oxymorphone via CYP2D6. Noroxycodone is metabolized to noroxymorphone through CYP2D6, and oxymorphone is metabolized to noroxymorphone by CYP3A4. However, oxycodone analgesia seems to rely primarily on the parent compound. Noroxycodone and oxymorphone also display affinity for $\mu$ opioid receptors. However, noroxycodone possesses only $17 \%$ of the potency of the parent compound. Oxymorphone, in spite of high affinity for $\mu$ opioid receptors, is produced in very small amounts. Noroxymorphone is produced in a significant amount and possesses significant affinity for opioid receptors. However, the blood-brain barrier is extremely impermeable to noroxymorphone in comparison to the parent compound; thus, its role in analgesia seems to be negligible. Low blood-brain barrier permeability is also characteristic of noroxycodone, oxymorphone and morphine [14].

In patients with hepatic impairment, $c_{\max }$ of oxycodone is $40 \%$ higher, and the AUC is $90 \%$ higher in comparison to patients with normal liver function. Therefore, in patients with liver cirrhosis or other hepatic diseases, the oxycodone dose should be reduced by half. Oxycodone is excreted through the kidneys. In patients with renal insufficiency, the oxycodone dose should also be reduced. Oxycodone concentrations in uraemic patients are higher than in subjects with normal renal function. In patients with renal failure, the oxycodone half-life is prolonged but it can range from 1.8 to $26 \mathrm{~h}$. The elimination of oxycodone metabolites (noroxycodone and oxymorphone) is also impaired in patients with renal failure [15].

CYP2D6 polymorphism does not influence oxycodone analgesia and adverse effects. Sertraline, which minimally inhibits CYP2D6, intensifies adverse effects of oxycodone (hallucinations, tremors), whereas fluoxetine and quinidine treatments significantly inhibit CYP2D6 and do not intensify oxycodone adverse effects. Oxycodone does not interact with amitriptyline, ciprofloxacin and levoquin but does reduce the oral bioavailability of cyclosporine by half. The CYP3A4 inducer rifampin greatly decreased oral and iv oxycodone AUC by $86 \%$ and $53 \%$, respectively, and modestly reduced analgesia with an increase of the plasma metabolite-to-parent compound ratios for noroxycodone and noroxymorphone. A pharmacodynamic interaction of oxycodone with benzodiazepines, neuroleptics and antidepressants may intensify oxycodone adverse effects, especially sedation, and in patients who are more sensitive to opioids, respiratory depression. The inhibition of both CYP2D6 and CYP3A4 but not CYP2D6 alone may significantly affect oxycodone pharmacokinetics [16].

Oxycodone may be given orally, s.c., i.v. and rectally. The bioavailability of rectal administration is similar to the oral route (61\%), but greater individual variability exists. In Poland oxycodone hydrochloride is available in CR tablets $(5,10,20$, 40 and $80 \mathrm{mg}$ ) and in ampoules (10 mg/1 ml and $20 \mathrm{mg} / 1 \mathrm{ml})$ 
for s.c. and i.v. administration. IR tablets are currently unavailable in Poland. CR oxycodone formulation provides analgesia for $12 \mathrm{~h}$ with a plasma half-life of $37 \mathrm{~min}$ (38\% of the dose) and an immediate analgesic effect for $1 \mathrm{~h}$ followed by a prolonged phase with a plasma half-life of $6.2 \mathrm{~h}(62 \%$ of the dose) [17].

\section{Discussion}

This case report illustrates problems encountered during the care of a patient with advanced prostate cancer with severe pain due to local tumour growth being the main complaint. The patient also complained of weakness and lack of appetite, the latter easily controlled with a small dose of dexamethasone as megestrol acetate was poorly tolerated in this patient [18]. His pain was associated with local tumour growth and the patient needed a suprapubic cystostomy procedure. His bone scintigraphy and laboratory tests (renal and hepatic function, electrolytes and full blood count) were normal.

OS allowed better pain relief and a decrease of drowsiness to be achieved. Although OS is usually performed at in-patient units, the patient did it at an out-patient clinic while being in constant touch with a physician. There is no clear direct conversion ratio between TB and oral oxycodone. Taking into account that there is a similar or even higher ratio between transdermal fentanyl and TB [19], the ratio between TB and oral morphine approximately equals $1: 100$. As for the oral route the dose of oral morphine is 1.5 or 2 times higher than that of oral oxycodone due to differences in oral bioavailability it might be assumed that for TB to oral oxycodone the ratio is about $1: 50$ or $1: 75$. The daily dose of TB $70 \mu \mathrm{g} / \mathrm{h}$ patch is $1.6 \mathrm{mg}$; thus it may be assumed that the equivalent oxycodone daily dose should be approximately $80 \mathrm{mg}$ [20]. However, there is a recommendation to start with a smaller dose than in equianalgesic tables as incomplete cross-tolerance between opioids exists [21]. It was also taken into account that the patient is treated in an out-patient clinic. Thus the oxycodone treatment was started with the daily dose of $20 \mathrm{mg}$ that was unsuccessful with respect to analgesia. However, an increase to the dose of $40 \mathrm{mg}$ daily provided satisfactory pain relief and less sedation.

It is difficult to explain why in the patient oxycodone provides better pain relief and less sedation than TB. Perhaps it is associated with oxycodone's mode of action on opioid receptors as in comparison to morphine less adverse effects from central nervous system are observed in clinical studies [22]. TB exerts an antagonist effect on $\kappa$ opioid receptors, while its main mode of action is believed to be mediated via $\mu$ opioid receptors [23]. The only adverse effect of oxycodone treatment observed in the patient was moderate constipation. Although it is controlled with lactulose the patient could probably benefit from administration of oxycodone/naloxone tablets [24]. Unfortunately, in Poland oxycodone/naloxone is not reimbursed for cancer patients and is thus relatively unavailable. Several studies have demonstrated efficacy of oxycodone in OS. In a prospective study of 186 palliative care patients treated with morphine 47 patients needed to change to an alternative opioid due to inadequate analgesia or adverse effects. In 37 patients a switch to oxycodone gave a positive outcome [25]. Oxycodone may also be administered as the first opioid [26].

To conclude, a successful and safe switch from TB to oral CR oxycodone is possible and in this patient it was effective, improving analgesia and reducing sedation. Controlled clinical studies should be undertaken to establish direct dose ratio between these commonly used opioids of step 3 of the analgesic ladder. In this case OS was safely conducted at an out-patient clinic with a significant improvement of the patient's quality of life.

\section{References}

1. Hanks GW, De Conno F, Cherny N, et al. Expert Working Group of the Research Network of the European Association for Palliative Care: Morphine and alternative opioids in cancer pain: the EAPC recommendations. Br J Cancer 2001; 84: 587-93.

2. Krajnik M, Wordliczek J, Dobrogowski J. Standardy leczenia bólu u chorego na nowotwór. Terapia 2010; 248-249: 3-9.

3. De Stoutz ND, Bruera E, Suazer-Almazor M. Opioid Rotation for Toxicity Reduction in Terminal Cancer Patients. J Pain Symptom Manage 1995; 10: 378-4.

4. Hardy JR, Quigley C, Ross JR. Opioid rotation. In: Opioids in Cancer Pain. Davis MP, Glare P, Quigley C, Hardy JR (ed.). Second Edition. Oxford University Press, Oxford 2009; 301-12.

5. Mercadante S. Opioid Rotation for Cancer Pain. Rationale and Clinical Aspects. Cancer 1999; 86: 1856-66.

6. Enting R, Oldenmenger W, van der Rijt C, et al. A prospective study evaluating the response of patients with unrelieved cancer pain to parenteral opioids. Cancer 2002; 94: 3049-56.

7. Mercadante S, Bruera E. Opioid switching: a systematic and critical review. Cancer Treat Rev 2006; 32: 304-15.

8. Leppert W. Postępy w leczeniu farmakologicznym bólu nowotworowego analgetykami opioidowymi. Współcz Onkol 2009; 13: 66-73.

9. Leppert $W$. The role of methadone in cancer pain treatment a review. Int J Clin Pract 2009; 63: 1095-109.

10. Ripamonti C, Groff L, Brunelli C, Polastri D, Stavrakis A, De Conno F. Switching From Morphine to Oral Methadone in treating Cancer Pain: What Is the Equianalgesic Dose Ratio? J Clin Oncol 1998; 16: 3216-21.

11. Leppert W. Methadone cardiotoxicity in pain management - an important issue for clinicians. Clinical Medicine Insights: Therapeutics 2010; 2: 1-6.

12. Boström E, Simmonson USH, Hammarlund-Udenaes M. In vivo blood-brain barrier transport of oxycodone in the rat: indications for active influx and implications for pharmacokinetics/pharmacodynamics. Drug Metabol Dis 2006; 34: 1624-31.

13. Riley J, Eisenberg E, Müller-Schwefe G, Drewers AM, Arendt-NieIsen L. Oxycodone: a review of its use in the management of pain. Curr Med Res Opin 2008; 24: 175-92.

14. Lalovic B, Kharasch E, Hoffer C, Risler L, Liu-Chen LY, Shen DD. Pharmacokinetics and pharmacodynamics of oral oxycodone in healthy human subjects: Role of circulating active metabolites. Clin Pharmacol Ther 2006; 79: 461-79.

15. Kaiko RF. Pharmacokinetics and pharmacodynamics of controlledrelease opioids. Acta Anaesth Scand 1997; 41: 166-74.

16. Grönlund J, Saari T, Hagelberg N, Neuvonen P, Laine K, Olkkola K. Effect of inhibition of cytochrome P450 enzymes 2D6 and 3A4 on the pharmacokinetics of intravenous oxycodone: a randomized, three-phase, crossover, placebo-controlled study. Clin Drug Invest 2011; 31: 143-53.

17. Lauretti GR, Oliveira GM, Pereira NL. Comparison of sustained-release morphine with sustained-release oxycodone in advanced cancer patients. Br J Cancer 2003; 89: 2027-30.

18. Mantovani G, Madeddu C. Cancer cachexia: medical management. Support Care Cancer 2010; 18: 1- 9.

19. Likar R, Krainer B, Sittl R. Challenging the equipotency calculation for transdermal buprenorphine: four case studies. Int J Clin Pract 2008; 62: 152-6. 
20. Mercadante S, Ferrera P, Villari P, Casuccio A, Intravaia G, Mangione $S$. Frequency, indications, outcomes, and predictive factors of opioid switching in an acute palliative care unit. J Pain Symptom Manage 2009; 37: 632-41.

21. Anderson R, Saiers JH, Abram S, Schlicht C. Accuracy in equianalgesic dosing: conversion dilemmas. J Pain Symptom Manage 2001; 21: 397-406.

22. Maddocks I, Somogyi A, Abbott F, Hayball P, Parker D. Attenuation of morphine-induced delirium in palliative care by substitution with infusion of oxycodone. J Pain Symptom Manage 1996; 12: 182-9.

23. Kögel B, Christoph T, Stra burger W, Friderichs E. Interaction of $\mu-$ opioid receptor agonists and antagonists with the analgesic effects of buprenorphine in mice. Eur J Pain 2005; 9: 599-61.

24. Leppert W. Role of oxycodone and oxycodone/naloxone in cancer pain management. Pharmacol Rep 2010; 62: 578-91.

25. Riley J, Ross JR, Rutter D, Wells AU, Goller K, du Bois R, Welsh K. No pain relief with morphine? Individual variation in sensitivity to morphine and the need to switch to an alternative opioid in cancer patients. Support Care Cancer 2006; 14: 56-64.

26. Tessaro L, Bandieri E, Costa G, Fornasier G, Iorno V, Pizza C, Pastacaldi G, Micheletto G. Use of Oxycodone Controlled-Release immediately after NSAIDs: a new approach to obtain good pain control. Eur Rev Med Pharmacol Sci 2010; 14: 113-21.

\section{Address for correspondence}

\section{Wojciech Leppert}

Chair and Department of Palliative Medicine

Poznan University of Medical Sciences

Osiedle Rusa 25 A

61-245 Poznan, Poland

tel./fax +48 618738303

e-mail: wojciechleppert@wp.pl 